\title{
Risk Factors Of Post-Operative Sore Throat In Patients Undergoing Emergency Caesarean Section Under General Anaesthesia With Endotracheal Tube - A Prospective Cohort Study
}

Shibu Sasidharan ( $\nabla$ shibusasi@gmail.com )

United Nations Organization Stabilization Mission in the Democratic Republic of the Congo https://orcid.org/0000-0003-2991-7595

Babitha Shibu

Amrita Institute of Medical Sciences and Research Centre

Harpreet Dhillon

MONUSCO

Suneeta Singh

MONUSCO

Divya Sinha

Armed Forces Medical College

Shifla Abdul Latheef

Armed Forces Medical College

Research article

Keywords: Postoperative sore throat, ETT, LSCS, Anaesthesia

Posted Date: July 13th, 2020

DOI: https://doi.org/10.21203/rs.3.rs-36768/v1

License: (c) (i) This work is licensed under a Creative Commons Attribution 4.0 International License.

Read Full License 


\section{Abstract}

Background: A prospective cohort study to study the risk factors of post-operative sore throat (POST) in pregnant patients undergoing emergency caesarean section under general anaesthesia with endotracheal tube.

Methods: 1000 pregnant patients were recruited to study the risk factors of POST over a period of 3 years. The data was analysed using SPSS-10 for Windows statistical software. Pearson's Chi Square test was the statistical test of significance.

Results: ETT size 7.0 decreased and ETT tube size 8.0 and above increased the risk for POST and hoarseness in the early postoperative period. The symptoms of POST surfaced mostly 8 hours after surgery (35.5\%). A low cuff pressure decreased the incidence of POST. Incidence of POST increases with the duration of surgery.

Conclusion: Incidence of POST in pregnant patients are comparable with general population and the factors that caused POST in general population caused the same in pregnant women, without any difference in characteristics, despite the complex change in physiology.

\section{Background}

Postoperative sore throat (POST) is a common complication of anaesthesia. It can lead to dissatisfaction and discomfort after surgery and can delay a patient's return to normal routine activities. Many factors can contribute to postoperative sore throat and the incidence has been found to vary with the method of airway management1. The incidence is the highest after tracheal intubation with endotracheal tube (ETT) and varies from $14.4-50 \%$, while after laryngeal mask airway (LMA) insertion the incidence has been found to vary from $5.8-34 \%$ and it is much less when a face mask is used for the maintenance of anaesthesia $1,2,3$. The wide variation in these figures is presumably due to different skills and techniques among anaesthetists and to differences between individual anaesthetists and patients in the definition of sore throat. The reporting of a sore throat is also affected by the method of interview, i.e., whether the questions regarding sore throat are asked directly or indirectly 4 . In a study, after indirect questioning of 129 patients, only two complained of sore throat, whereas after direct questioning of 113 patients, 28 complained of sore throat ${ }^{5}$. This difference may be due to the fact that patients concentrate on symptoms directly related to the operative site and do not immediately associate sore throat with anaesthesia and surgery. Pregnancy is a psychologically stressful time for the carrying mothers ${ }^{6}$. A surgery during the end of pregnancy like lower segment caesarean section (LSCS) causes further apprehension.

This study was done to evaluate the incidence of sore throat after general anaesthesia given for emergency LSCS and to analyse the contributory factors for the same. As mentioned above, there are many factors contributing to POST. Pregnancy is a characteristic period characterized by compound 
physiologic changes which may affect the oral and genital mucosal surfaces and arise as the result of the unique hormonal milieu of pregnancy ${ }^{7}$. The present study was done to determine the incidence of post-operative sore throat (POST) after general anaesthesia in emergency LSCS patients in our hospital population and to determine and analyse the contributory factors for the same. By filling these gaps in our knowledge, we may be able to reduce the risk of unnecessary suffering from POST for mothers undergoing general anesthesia, who are already in great deal of stress. This will also help us in the long run to improve patient satisfaction and provide good anaesthetic care.

\section{Methods}

Criteria for Selection of Subjects

1. Ages of 18 and 35 years

2. Classified as ASA physical status II (for pregnancy), without any co-morbidity

3. Undergoing emergency LSCS

4. Patients were not considered for the study if they had any of the conditions listed in exclusion criteria.

Criteria for Exclusion

1. Pre-existing sore throat

2. Nasogastric tube in-situ

3. Recent anti-inflammatory medications

4. Guedels or nasal pharyngeal airway (bite block is acceptable)

5. Position other than supine or lithotomy

6. Coughing or bucking on intubation

7. Re-intubation

8. Postoperative vomiting

9. Unable to communicate with the researcher

10. Undergoing any simultaneous other surgical procedure

\section{Study Characteristics}

A prospective cohort study was done on 1000 ladies who underwent emergency LSCS in a tertiary level teaching hospital over a three year period, and were recruited into the study after they met the inclusion criteria. The study was approved by the ethics committee.

Informed consent was obtained as follows: When eligible patients were referred to surgery, they were evaluated for inclusion. On the day of the surgery, before any premedication was administered, the researcher visited the patients and written consent was obtained. The aim and intentions of the study 
were carefully explained, as well as, the scales used and the reasons why patients' reported outcomes were collected several times postoperatively.

\section{Methodology.}

Patients' age, weight, and ASA physical status were recorded on a standardized information sheet. The drug used for muscle relaxation, use of Inj. Glycopyrolate, onset time of POST, type of ETT, no of attempts, weight of the patient, ID of tube, cuff pressure \& hoarseness of voice were recorded. No double lumen ETT will be used.

A lubricant jelly was applied to the ETT. Standard institutional methods were used for placement of ETTs. After ETT placement, patient's lungs were mechanically ventilated. Rapid sequence induction and intubation(RSI) was done in all cases. After intubation anaesthesia was maintained with an inhalation agent in a mixture of oxygen and nitrous oxide keeping MAC not exceeding 1 . Airway devices were removed when patients were able to open their eyes to command. Cuff pressure was recorded using a cuff manometer.

The clinical management of the patients were left to the discretion of the anaesthetist. Modified Aldrete Recovery Score was used to decide discharge of the patient. Patients were interviewed at 0, 0.5, 1, 2 and 8 hours and the incidence of sore throat was noted by using standardized direct questions. Patients were asked whether they had a sore throat and if they had any hoarseness of voice.

\section{Outcome Measures}

Postoperative sore throat and postoperative hoarseness were investigated in all studies, as per the grading scale below. Other measurements included discomfort from symptoms and localizations of POST.

\section{Postoperative Sore Throat}

Determining the incidence of POST was the primary aim. A subjective four-grade scale was used with a common-cold as a point of reference:

$0=$ No sore throat

$1=$ Mild sore throat (less than with a cold)

$2=$ Moderate sore throat (as with a cold)

$3=$ Severe (more severe than with a cold).

The degree of POST was evaluated several different times during the post-operative period.

\section{Discomfort in throat}


To investigate if the emergence of airway symptoms uncomfortable for the patient, a four-grade scale was used:

$0=$ No discomfort

$1=$ Mild discomfort

$2=$ Moderate discomfort

3= Severe discomfort

The degree of discomfort was evaluated several different times during the postoperative period. Association with eating, drinking and speaking were also noted.

\section{Localization of POST}

In order to determine where the sore throat was localized in the throat, a photograph was developed by the researcher (Figure 1, 2). Initially, ten persons who had reported POST after anesthesia were contacted irrespective of whether they had had an ETT or an LMA. They were asked to locate POST, and requested to describe the symptom by using an adjective that they found easy to understand. They described the location in the throat, that had been sore (the pharynx, and above or below the larynx). None of the ten persons described pain in the mouth, a category that included the lips and tongue, but we added this category. One patient had POST for 14 days, high up in her chest, after an intubation. The researcher interpreted this likely to be in the carina, and therefore a fifth category was added (high up in the chest). The photograph was then shown to ten new patients in the PACU, and they all confirmed that it was easy to under-stand and use (face and content validity). The color photograph was then laminated.

Sample size: The sample size was calculated to estimate $95 \%$ confidence interval for proportion of patients developing sore throat after endotracheal intubation, with $5 \%$ error of margin on either side of the truth, assuming that $22 \%$ of such patients will develop POST ${ }^{22}$, as per previous studies. The sample size works out to be 323. However, there has not been enough studies done on pregnant ladies undergoing emergency LSCS, so 1000 patients were studied.

\section{Hoarseness of Voice}

A subjective four grade scoring was used to grade hoarseness:

0 - No evidence of hoarseness at any point after the operation

1 - Hoarseness noted by patient

2 - Mild hoarseness of voive

3 - Severe hoarsenes of voice 


\section{Statistical Analysis}

Continuous variables were compared between patients with and without sore throat using descriptive statistics and dichotomous variables using proportions. Pearson's Chi Square test was the statistical test of significance. We used multiple logistic regression modelling with backward stepwise variable selection to identify factors associated with sore throat. A p-value less than 0.05 was considered statistically significant. The data was analysed using SPSS 10 for Windows statistical software.

\section{Results}

A total of 1000 patients were included in the study, and all 1000 patients were analysed. All patients had met the inclusion criteria and they were assessed for drug used for muscle relaxation, use of Inj. Glycopyrolate, onset time of POST, type of ETT, no of attempts, weight of the patient, ID of tube, cuff pressure \& hoarseness of voice. Table 1 shows descriptive statistics. Table 2 onwards shows the frequency distribution of the study. 
Table 1

Descriptive Statistics

\begin{tabular}{|c|c|c|c|c|}
\hline & \multicolumn{2}{|c|}{ Age } & \multicolumn{2}{|c|}{ Weight } \\
\hline Sample size & \multicolumn{2}{|c|}{1000} & \multicolumn{2}{|c|}{1000} \\
\hline Lowest value & \multicolumn{2}{|l|}{18} & \multicolumn{2}{|l|}{41} \\
\hline Highest value & \multicolumn{2}{|l|}{82} & \multicolumn{2}{|l|}{86} \\
\hline Arithmetic mean & \multicolumn{2}{|c|}{45.916} & \multicolumn{2}{|c|}{61.077} \\
\hline $95 \% \mathrm{Cl}$ for the mean & \multicolumn{2}{|c|}{45.0025 to 46.8295} & \multicolumn{2}{|c|}{60.5894 to 61.5646} \\
\hline Median & \multicolumn{2}{|l|}{49} & \multicolumn{2}{|l|}{61} \\
\hline $95 \% \mathrm{Cl}$ for the median & \multicolumn{2}{|c|}{48.0000 to 50.0000} & \multicolumn{2}{|c|}{61.0000 to 62.0000} \\
\hline Variance & \multicolumn{2}{|c|}{216.7036} & \multicolumn{2}{|c|}{61.7408} \\
\hline Standard deviation & \multicolumn{2}{|c|}{14.7209} & \multicolumn{2}{|c|}{7.8575} \\
\hline Relative standard deviation & \multicolumn{2}{|c|}{$0.3206(32.06 \%)$} & \multicolumn{2}{|c|}{$0.1286(12.86 \%)$} \\
\hline Standard error of the mean & \multicolumn{2}{|c|}{0.4655} & \multicolumn{2}{|c|}{0.2485} \\
\hline Coefficient of Skewness & \multicolumn{2}{|c|}{$-0.2766(P=0.0004)$} & \multicolumn{2}{|c|}{$0.0001130(P=0.9988)$} \\
\hline Coefficient of Kurtosis & \multicolumn{2}{|c|}{$-1.1986(P<0.0001)$} & \multicolumn{2}{|c|}{$-0.1881(P=0.2011)$} \\
\hline $\begin{array}{l}\text { D'Agostino-Pearson test } \\
\text { for Normal distribution }\end{array}$ & \multicolumn{2}{|c|}{ Reject Normality $(P<0.0001)$} & \multicolumn{2}{|c|}{ Accept Normality $(P=0.4416)$} \\
\hline Percentiles & & 95\% Confidence Interval & & 95\% Confidence Interval \\
\hline 25 & 32 & 30.00 to 32.56 & 54 & 54.00 to 56.00 \\
\hline 75 & 60 & 58.00 to 60.00 & 67 & 65.43 to 67.00 \\
\hline
\end{tabular}


Table 2

Muscle Relaxant vs. POST

\begin{tabular}{|c|c|c|c|c|c|}
\hline \multirow[t]{2}{*}{ Muscle Relaxant } & \multicolumn{3}{|c|}{ POST } & \multirow[t]{2}{*}{ Incidence } & \multirow{2}{*}{$\begin{array}{l}\text { P-Value* } \\
0.711\end{array}$} \\
\hline & NO & YES & Total & & \\
\hline Atracurium & 262 & 91 & 353 & $25.8 \%$ & \\
\hline Rocuronium & 45 & 18 & 63 & $28.6 \%$ & \\
\hline Vecuronium & 442 & 142 & 584 & $24.3 \%$ & \\
\hline Total & 749 & 251 & 1000 & $25.1 \%$ & \\
\hline
\end{tabular}

\section{Muscle Relaxant vs. POST}

Table 2 shows the association of the type of muscle relaxant used to the prevalence of POST. Inj Atracurium, Vecuronium and Rocuronium were studied to check for association and was found as not significant.

\section{Inj. Glycopyrolate and POST}

Table 3 shows association of POST with using Inj Glycopyrolate using induction. It was found to be nonsignificant.

Table 3

Use of Glycopyrolate and POST

\begin{tabular}{|lllllll|}
\hline \multicolumn{5}{|c}{ POST } & \multicolumn{5}{c|}{ Incidence } & P-Value \\
\cline { 1 - 5 } Inj. Glyco & NO & YES & Total & & & \\
\cline { 1 - 6 } No & 68 & 20 & 88 & $22.7 \%$ & Chi-Squared Test & 0.591 \\
\hline Yes & 681 & 231 & 912 & $25.3 \%$ & Fisher's Exact Test (Sig. (1-sided)) & 0.699 \\
& 749 & 251 & 1000 & $25.1 \%$ & Fisher's Exact Test (Sig. (2-sided)) & 0.347 \\
\hline
\end{tabular}

\section{Onset Time Frame vs. POST}

Table 4 shows the time of onset of POST after LSCS. It was seen that the symptoms of POST surfaced most frequently at $8 \mathrm{hrs}$ after extubation. Immediately after extubation, very few patients complained of POST. 
Table 4

Onset time of POST

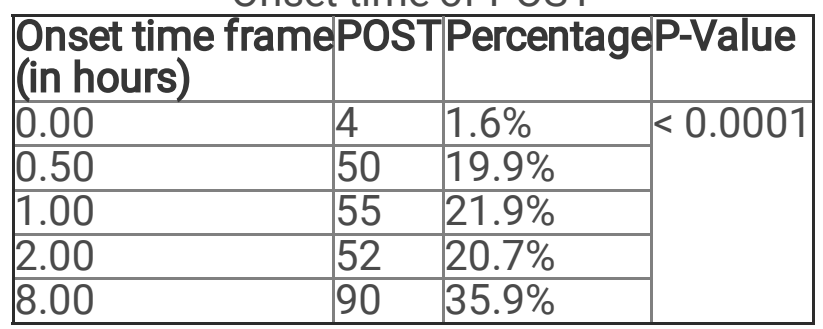

\section{ETT Type vs. POST}

Table 5 interprets the type of ETT and POST. PVC tubes and FM tubes were compared and there was no significant difference in both in causing POST.

Table 5

Type of ETT vs. POST

\begin{tabular}{|c|c|c|c|}
\hline \multirow{2}{*}{\multicolumn{3}{|c|}{\begin{tabular}{|l|} 
ETT TypePOST \\
NO YESTotal \\
\end{tabular}}} & \multirow{2}{*}{ P-Value } \\
\hline & & & \\
\hline PVC & 591205796 & Fisher's Exact Test (Sig. (1-s & .367 \\
\hline Total & 7492511000 & Fisher's Exact Test (Si & .198 \\
\hline
\end{tabular}

\section{Number of attempts vs. POST}

An 'Attempt' was defined as a single advanced airway maneuver (e.g., beginning with the insertion of the device such as laryngoscope into patient's mouth or nose, and ending when the device was removed) ${ }^{22}$.With incresing number of attempts, the chances for airwar and soft tissue injury increases, whish is one of the mechanisms for developing a POST. Table 6 shows that with increasing number of attempts, the incidence of POST also increased and is strongly significant.

Table 6

No of attempts vs. POST

\begin{tabular}{|l|l|l|l|l|l|}
\hline \multirow{2}{*}{ Attempts } & POST & \multicolumn{1}{|l|}{ Total| Incidence P-Value } \\
\cline { 2 - 5 } & NO & YES Total & & \\
\hline 1 & 677 & 201 & 878 & $22.9 \%$ & $<0.0001$ \\
\hline 2 & 60 & 28 & 88 & $31.8 \%$ & \\
\hline 3 & 12 & 22 & 34 & $64.7 \%$ & \\
\hline & 749 & 251 & 1000 & $25.1 \%$ & \\
\hline
\end{tabular}

Table 7

Weight of patients vs. POST

\begin{tabular}{|l|l|l|l|l|l|}
\hline \multirow{2}{*}{ Weight Groups } & \multicolumn{2}{l}{ POST } & Incidence P-Value \\
\cline { 2 - 5 } & NO & YESTOtal & & \\
\hline $41.00-50.00$ & 41 & 6 & 47 & $12.8 \%$ & 0.178 \\
\hline $51.00-60.00$ & 306 & 108 & 414 & $26.1 \%$ & \\
\hline $61.00-70.00$ & 310105 & 415 & $25.3 \%$ & \\
\hline $71.00-80.00$ & 86 & 32 & 118 & $27.1 \%$ & \\
\hline $81.00-90.00$ & 6 & 0 & 6 & $0.0 \%$ & \\
\hline Total & 749251 & 1000 & $25.1 \%$ & \\
\hline
\end{tabular}

Weight Group vs. POST

Table 6 shows that weight is not an independent risk factor to develop sore throat. It was seen that morbidly obese patients did not necessarily develop sore throat after intubation.

\section{ETT ID vs. POST}

Table 8 shows the association of the internal diameter of the ETT to causation of POST. It is strongly significant with increasing POST with increasing ID. 
Table 8

ETT Internal Diameter (ID) vs. POST

\begin{tabular}{|c|c|c|c|c|}
\hline ETT & POST & & Incidenc & P-Value \\
\hline & NO YES & STotal & & \\
\hline & \begin{tabular}{l|l}
6 & 0 \\
\end{tabular} & 6 & $0.0 \%$ & $<0.0001$ \\
\hline 1 & 15625 & 181 & $13.8 \%$ & \\
\hline .0 & 14650 & 196 & $25.5 \%$ & \\
\hline & 441176 & 617 & $28.5 \%$ & \\
\hline 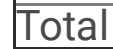 & 749251 & & $25.1 \%$ & \\
\hline
\end{tabular}

\section{Cuff Pressure vs. POST}

Table 9 concludes that reducing ETT cuff pressures to $20 \mathrm{~mm} \mathrm{Hg}$ may be helpful in decreasing POST. Cuff pressure shows a strong correlation to the incidence of sore throat. Greater the pressure in the cuff, greater prevalence of POST was noted.

Table 9

Cuff pressure vs. POST

\begin{tabular}{|l|l|l|l|l|l|}
\hline Cuff Pressure & POST & Incidence P-Value \\
& NO & Yes & Total & & \\
\hline $20-23$ & 75 & 4 & 89 & $5.3 \%$ & $<0.0001$ \\
\hline $24-26$ & 272 & 27 & 299 & $9.0 \%$ & \\
\hline $27-30$ & 242 & 113 & 355 & $31.8 \%$ & \\
\cline { 2 - 2 } & 13 & 73 & 86 & $84.9 \%$ & \\
\hline $34-37$ & 0 & 5 & 5 & $100.0 \%$ & \\
\hline Total & 602 & 232834 & $27.8 \%$ & \\
\hline
\end{tabular}

\section{Hoarseness of Voice vs. POST}

Table 10 shows the incidence of hoarseness of voice in cases of POST. 221 patients had mild hoarseness of voice and it was found to be significant in our study.

\section{Table 10}

Hoarseness of voice vs. POST

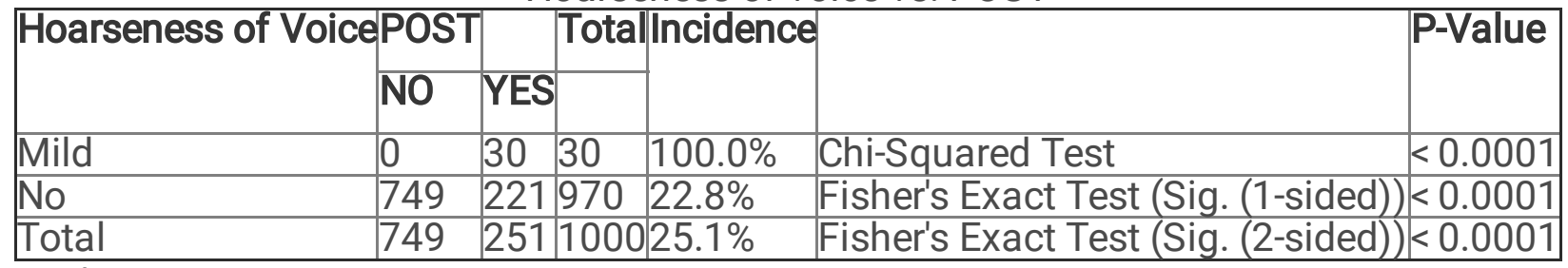

\section{Discussion}

The incidence of postoperative sore throat (POST) is as high as $100 \%$ in some studies, and is ranked as a patient's 8th most undesirable postoperative event ${ }^{9}$. The method of airway management has been shown to be the most significant predictor of POST, but the selection of an airway device is a multifactorial verdict customized upon the patient and the procedure. Cognizance of the variables linked with an increased incidence of POST can allow care givers to minimalize combinations of risk factors, reduce the incidence and severity of POST, and improve a patients anesthesia experience.

We compared a number of patients and perioperative factors and their significance in contributing to POST. We analyzed drug used for muscle relaxation, use of Inj. Glycopyrolate, onset time of POST, type of ETT, no of attempts, weight of the patient, ID of tube, cuff pressure \& hoarseness of voice. We 
documented the incidence of POST in the cases and also hoarseness of voice. The time of onset was noted and also the severity of POST.

Many findings in the study matched the literature in results while others brought out differing conclusions.

Christenson reported the greatest frequency of POST in the age group of 30-49 years ${ }^{10}$. Higgings also reported an inverse association between age and sore throat ${ }^{11}$. In our study all of patients belonged in the young age group. However, the incidence of sore-throat was maximum in the age group 31-35 years. This equals with the studies done in the past.

P Biro et al in their analysis - Complaints of sore throat after tracheal intubation: a prospective evaluation ${ }^{12}$, concluded that the female gender has greater incidence of POST. Our results however show that gender does not have a significant role to play in POS because the incidence was comparable to the studies that have been conducted in males and the general population $3,11,12,20$.

The appropriate ETT size in women and men is still unclear and debated in the anesthesia community ${ }^{13}$. However, there seems to be some evidence that women benefit from a smaller size ETT ${ }^{14}$. In our study, the incidence of POST was highest with the ETT ID 8.5 and lowest with ID 7.

To the best of our information only Joorgensen et al. ${ }^{15}$ have studied the location of POST as assed by the patient. One reason for not asking about the precise location of POST may be that it is difficult to explain correctly. Despite the complexity of pain localization, we did find that our patients seem to be able to localize pain in the throat. We found that more patients located the pain below the larynx after an ETT compared to an LMA, probably due to the design and shape of the cuff in the ETT ${ }^{16}$. However, pain above the larynx after an ETT could also be caused by laryngoscopy ${ }^{17,18}$.

Higgings et al reported a direct association between duration of surgery and sore throat ${ }^{11}$. In an other study by Sumathi, P. A., et al. they concluded that the incidence of developing POST was nearly $85 \%$ if the surgery time exceeded $>240 \min ^{19}$.

The drugs used for inducing and maintaining anesthesia and their propensity to cause POST were studied in great detail by many researchers. We in our study tried to find the association with commonly used muscle relaxants. Suxamethonium was not used in any patient who had been included in the study. From our study, we concluded that although $28.6 \%$ of the patients who had POST was intubated with Rocuronium, the correlation was not significant, with a p-value of 0.711 . Use of suxamethonium for intubation was associated with POST in a significant proportions of patients as per earlier studies with an incidence as high as $62 \%$. No other anesthetic drug was found to have an association with sore throat.

PA Stratelak in his research - The effect of glycopyrrolate premedication on postoperative sore throat ${ }^{20}$ concluded that there is a direct positive association between the drug and POST. This association was however not seen in our study and we concluded that Inj. Glycopyrolate does not cause POST. 
Higgins in his research documented that - Patients with ASA physical status III had a significantly smaller risk of developing sore throat compared with patients with ASA physical status I and II (OR 0.45)(11). In our study we had excluded all ASA III patients. However on analysis of the incidence of POST in ASA I \& II patients, no significant correlation could be found and $p$-values for the same were 0.076 and 0.086 respectively.

\section{Study limitations}

One weakness of our study is the fact that the ETT insertion technique can vary between anaesthetists and this was not standardized. However, the strength of this study design is that the results reflect a reallife situation with no attempts to influence insertion of the ETT or to control the experience of the personnel in any way. We did not record coughing and bucking which can affect the result. Hemodynamic fluctuations were not included in the study. We did not note the gestational age of the mother in our study. Its association to POST cannot be commented upon. Finally, we did not note the analgesic consumption of patients - in the ward or at home.

\section{Summary \& Conclusion}

Endotracheal tube size 7.0 decreased postoperative sore throat in pregnant women undergoing LSCS, who are more prone to POST, in the early postoperative period. Endotracheal tube size 8.0 and above increased the risk for postoperative hoarseness in both sexes in the early postoperative period. The type of muscle relaxant used did not have a bearing on the incidence of POST.

Administration of Inj Glycopyrolate had no bearing on POST. The symptoms of POST surfaced mostly at 1 hour after surgery. In contrast to earlier literature that said that females have a greater chance of developing POST, we found that men developed more POST than women. A low cuff pressure decreased the incidence of sore throat. With the increase in attempts in intubation, the chances of POST also increases. Sore throat lasted approximately three days after an ETT was removed. Hoarseness of voice was a very rare complication of endotracheal intubation with a very less prevalence.

\section{Abbreviations}

Nil

\section{Declarations}

\section{ETHICAL APPROVAL AND CONSENT TO PARTICIPATE}

Approval taken from Ethics Committee of the hospital. Project No. 211/14 dated 05 June 2017. Informed written consent taken from all patients who participated in the study. 
Taken from authorities. Permission also taken from the gentleman who consented to pose for the picture.

\section{Availability of data and materials}

Yes

\section{AUTHORS' CONTRIBUTIONS}

All authors have contributed partly or wholly in the study.

SS- Study conception and design, Acquisition of data, Analysis and interpretation of data, Drafting of manuscript, Critical revision.

BM, HD- Study conception and design, Analysis and interpretation of data, Drafting of manuscript, Critical revision

SuS, DS- Drafting of manuscript, Critical revision

\section{COMPETING INTERESTS}

Nil

\section{FUNDING}

Nil

\section{ACKNOWLEDGEMENTS}

Nil

\section{AUTHORS' INFORMATION}

As in title page

\section{References}

1. Sasidharan S. "To Study The Incidence And Risk Factors Of Post-Operative Sore Throat In Patients Undergoing Elective Surgeries Under General Anaesthesia With Endotracheal Tube." Journal. .

2. McHardy FE, Chung F. Postoperative sore throat: cause, prevention and treatment. Anaesthesia. 1999;54:444-53.

3. Joshi GP, Inagaki Y, White PF, Taylor-Kennedy L, Gevirtz C, et al. Use of the laryngeal mask airway as an alternative to the tracheal tube during ambulatory anaesthesia. Anesth Analg. 1997;85:573-77.

4. Higgins PP, Chung F, Mezei G. Postoperative sore throat after ambulatory surgery. Brit J Anaesth. 2002;88(4):582-4. 
5. Harding CJ, McVey FK. Interview method affects incidence of postoperative sore throat. Anaesthesia. 1987;42:1104-7.

6. Bibring GL. Some considerations of the psychological processes in pregnancy. The psychoanalytic Study of the Child. 1959;14(1):113-21.

7. Ramos-e-Silva M, Martins NR. and George Kroumpouzos. "Oral and vulvovaginal changes in pregnancy. Clin Dermatol. 2016;34(3):353-8.

8. Stratelak PATRICIAA, White WENDY. and D. A. V. I. D. Wenzel. "The effect of glycopyrrolate premedication on postoperative sore throat. AANA J. 1996;64:545-56.

9. Christensen AM, et al. "Postoperative throat complaints after tracheal intubation.". Br J Anaesth. 1994;73(6):786-7.

10. Christensen AM, et al. "Postoperative throat complaints after tracheal intubation.". Br J Anaesth. 1994;73(6):786-7.

11. Higgins PP, Chung F, Mezei G. Postoperative sore throat after ambulatory surgery. $\mathrm{Br} \mathrm{J}$ Anaesth. 2002;88(4):582-4.

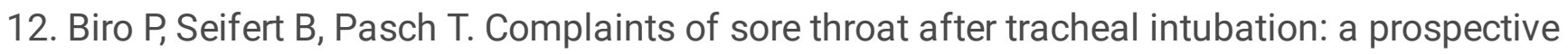
evaluation. Eur J Anaesthesiol. 2005;22(04):307-11.

13. Farrow S, Farrow C, Soni N. Size matters: choosing the right tracheal tube. Anaesthesia. 2012;67:815-9.

14. Hu B, Bao R, Wang X, Liu S, Tao T, Xie Q, Yu X, Li J, Bo L, Deng X. The size of endotracheal tube and sore throat after surgery: a systematic review and meta-analysis. PLoS ONE. 2013;8:e74467.

15. Joorgensen LN, Weber M, Pedersen A, Munster M. No increased incidence of postoperative sore throat after administration of suxamethonium in endotracheal anaesthesia. Acta Anaesthesiol Scand. 1987;31:768-70.

16. Loeser EA, Orr DL 2nd, Bennett GM, Stanley TH. Endotracheal tube cuff design and postoperative sore throat. Anesthesiology. 1976;45:684-7.

17. Brimacombe J, Holyoake L, Keller C, Brimacombe N, Scully M, Barry J, Talbutt P, Sartain J, McMahon P. Pharyngolaryngeal, neck, and jaw discomfort after anesthesia with the face mask and laryngeal mask airway at high and low cuff volumes in males and females. Anesthesiology. 2000;93:26-31.

18. Jaensson M, Gupta A, Nilsson UG. Gender differences in risk factors for airway symptoms following tracheal intubation. Acta Anaesthesiol Scand. 2012;56:1306-13.

19. Sumathi PA, et al. Controlled comparison between betamethasone gel and lidocaine jelly applied over tracheal tube to reduce postoperative sore throat, cough, and hoarseness of voice. $\mathrm{Br} \mathrm{J}$ Anaesth. 2008;100(2):215-8.

20. Stratelak PATRICIAA, White WENDY. and D. A. V. I. D. Wenzel. "The effect of glycopyrrolate premedication on postoperative sore throat. AANA J. 1996;64:545-56.

21. Joshi GP, Inagaki Y, White PF, et al. Use of the laryngeal mask airway as an alternative to the tracheal tube during ambulatory anesthesia. Anesth Analg. 1997;85:573-7. 
22. Lee $\mathrm{JH}$, Turner $\mathrm{DA}$, Kamat $\mathrm{P}$, et al. The number of tracheal intubation attempts matters! A prospective multi-institutional pediatric observational study. BMC Pediatr. 2016;16:58. Published 2016 Apr 29. doi:10.1186/s12887-016-0593-y.

\section{Figures}

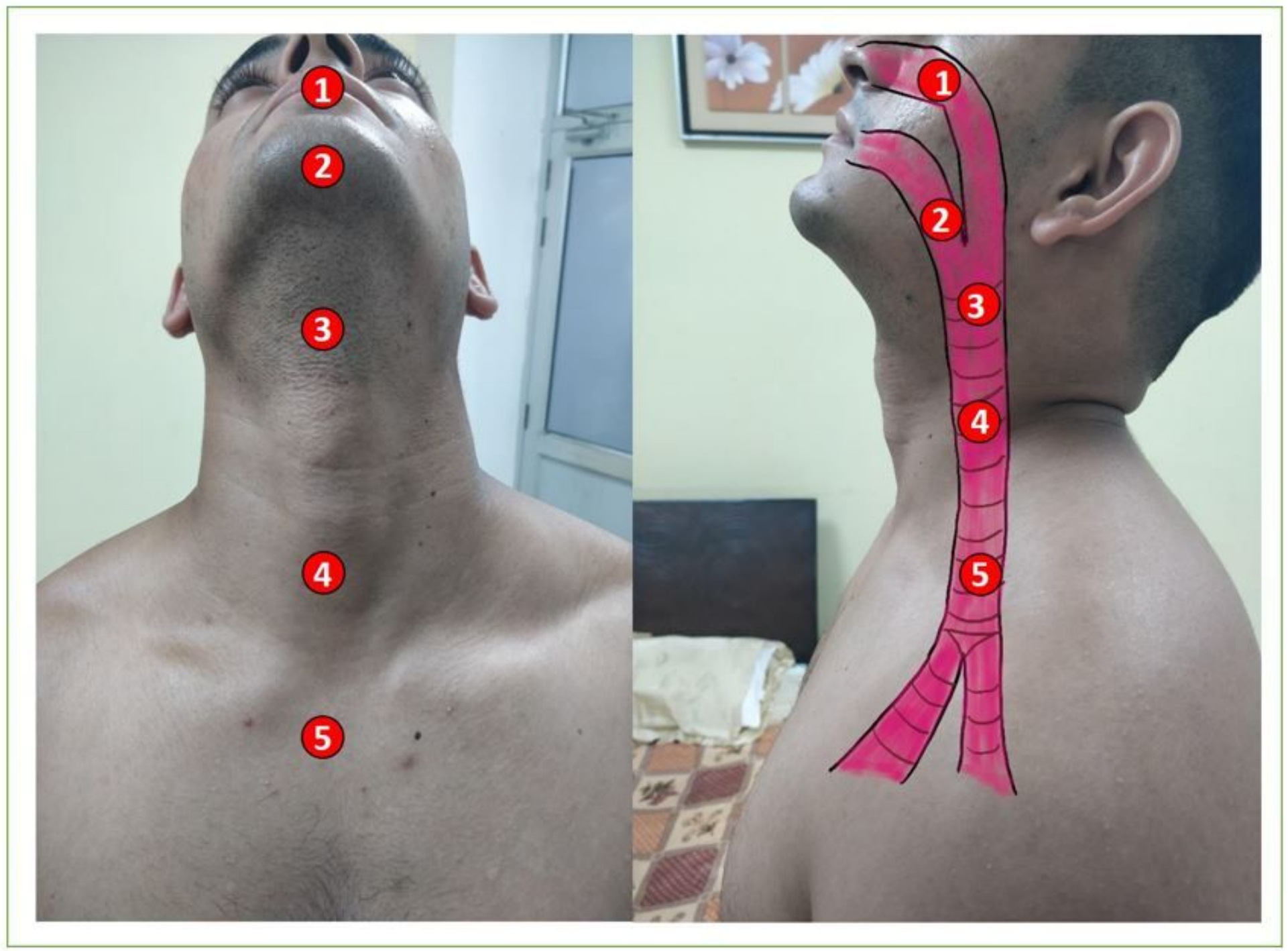

\section{Figure 1}

Photograph for localization of the sore throat-frontal and lateral views of a man. 1. In the mouth. 2. In the pharynx. 3. Above the larynx. 4. Below the larynx. 5. High up in the chest 


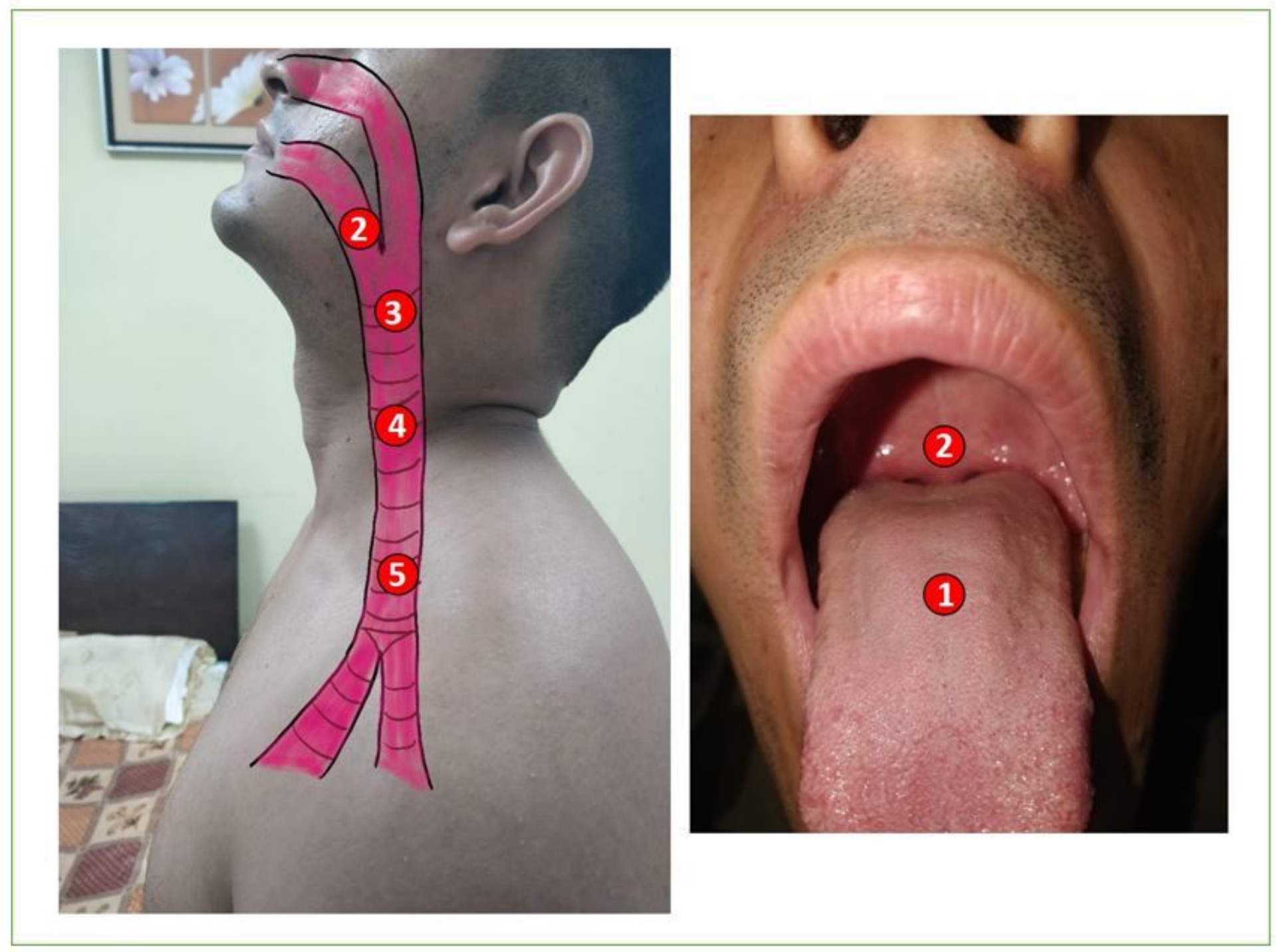

\section{Figure 2}

Photograph of localization of the sore throat- a lateral view of a man (same as fig.1) and in the mouth. 1. In the mouth. 2. In the pharynx. 